\title{
The potential of medical device industry in technological and economical context
}

\author{
This article was published in the following Dove Press journal: \\ Therapeutics and Clinical Risk Management \\ 3 October 2015 \\ Number of times this article has been viewed
}

\author{
Petra Maresova' \\ Marek Penhaker ${ }^{1,2}$ \\ Ali Selamat ${ }^{1,3}$ \\ Kamil Kuca ${ }^{1,4}$ \\ 'Faculty of Informatics and \\ Management, University of Hradec \\ Králové, Hradec Králové, Czech \\ Republic; ${ }^{2}$ Department of Cybernetics \\ and Biomedical Engineering, Faculty of \\ Electrical Engineering and Computer \\ Science, Technical University of \\ Ostrava, Poruba, Czech Republic; \\ ${ }^{3}$ Faculty of Computing, Universiti \\ Teknologi Malaysia, Johor Bahru, Johor, \\ Malaysia; ${ }^{4}$ Center for Biomedical \\ Research, University Hospital Hradec \\ Králové, Hradec Králové, Czech \\ Republic
}

\begin{abstract}
The high quality of public health improves not only healthy life expectancy, but also the productivity of labor. The most important part of the health care sector is the medical technology industry. The aim of this study is to analyze the current situation in the medical device industry in Europe, its potential strengths and weaknesses in the context of topical economic and demographic development. The contribution specifies an analysis of the economic state of the medical device industry in the context of demographic development of European Union's macroeconomic indicators and views of experts in the field of medical device development, concerning the opportunities for entities involved in the medical device market. There is fierce competition on the European market. The innovative activity is stable and well regulated by responsible authorities. Worldwide, the medical device market is expected to grow.
\end{abstract}

Keywords: technology context, medical device, Europe, expenditure, review

\section{Introduction}

With respect to the demographic trend in Europe, health care and the development of health devices are hot issues. Several studies evaluate the prospects of medical interventions, ${ }^{1,2}$ economic effectiveness of innovative technologies in health care, ${ }^{3}$ or Health technology assessment in chosen European countries. In order to implement innovative technologies in practice, it is becoming extremely important to be cost conscious and effective as well as to know and follow new guidelines in health care. ${ }^{4}$

Many studies have proved that there is a relation between health and the economic development of countries. ${ }^{5-9}$ Improved public health leads to healthy life expectancy, which is then reflected in increased quality and productivity of labor. It is therefore vital to invest in the health of working people in order to prolong their active life and achieve better health. This investment may also decrease future costs of treating patients suffering from preventable diseases. The healthier the individual people are, the more and longer they are able to be at the labor market. Approximately one in four currently employed people (23.5\%) suffers from a chronic condition, which limits them in doing their daily activities. It is the more so in latter stages of their lives when their participation in the labor market is markedly lower. ${ }^{10}$ Moreover, there is an increased incidence of multiple diseases (comorbidity) at higher age. As a result, the pressure on health systems and social care structures in terms of demand for care increases.

In the context of this development, the problem of investments in the medical device industry as a part of health care becomes more significant. Medical devices are irreplaceable in diagnostics, prevention, monitoring, and medical treatment of diseases and in increasing the quality of life of persons with a health problem. ${ }^{11}$ Variability and innovativeness of this industry significantly contribute to an increase in the quality and efficiency of health care. The aim of this contribution is to analyze and specify the
Correspondence: Kamil Kuca

Center for Biomedical Research,

University Hospital Hradec Králové,

Sokolská 58I, Hradec Králové 50005,

Czech Republic

Tel +420603289166

Fax +420495835200

Email kamil.kuca@fnhk.cz
Therapeutics and Clinical Risk Management 20I5:I I I505-15I4 1505

Dovepress

http://dx.doi.org//0.2147/TCRM.S88574
cC) (i) (c) 2015 Maresova et al. This work is published by Dove Medical Press Limited, and licensed under Creative Commons Attribution - Non Commercial (unported, v3.0) LY License. The full terms of the License are available at http://creativecommons.org/licenses/by-nc/3.0/. Non-commercial uses of the work are permitted without any further permission from Dove Medical Press Limited, provided the work is properly attributed. Permissions beyond the scope of the License are administered by Dove Medical Press Limited. Information on
how to request permission may be found at: http://www.dovepress.com/permissions.php 
current situation in the medical device industry, its potential strengths and weaknesses in the context of topical economic and demographic development.

\section{Research methods}

The following methods are used in the issue: retrospective analysis (of demographic data, data related to the growth of medical device market), structured interviews with experts, and analysis of external environment. External analysis focuses on the surrounding environment, aims at the opportunities, threats, as well as other factors that will influence the future strategy of this industry. This analysis specifies political, economic, social, and technological factors (therefore, it is also called PEST analysis). The individual factors are arranged according to their importance as for the expected future state of the industry. The analysis of political factors monitors laws, restrictions, and conditions significant for the future development of the industry, including legislation, political stability, tax policy, and integration policy. Among the most important economic factors are gross domestic product (GDP), interest rate, or inflation. These factors specify the performance of the industry. Social factors are important, in particular, for companies involved in selling products to the end consumer. In this area, it is vital to understand demographic stratification, lifestyle, income, and religious issues. Technological changes may suddenly and dramatically influence the whole industry. Among the monitored factors are government support to research and development (R\&D), general technological level, new discoveries, and inventions. The analyses of the external environment served as the basis for forming the so-called SWOT matrix (strengths, weaknesses, opportunities, and threats). The SWOT analysis was devised by Albert Humpley in the 1960s. The SWOT analysis process is usually divided into three basic stages:

- Identification and assessment of strengths and weaknesses, which are internal to the organization.

- Identification and assessment of opportunities and threats, which are external to the organization.

- Creating the SWOT matrix.

Strengths are internal resources of the company, its positive attributes, or assets. Weaknesses are aspects of the organization that need improvement and cause competitive disadvantage. Opportunities are external attractive factors that the organization can benefit from as they increase demand or can better satisfy the customer. Threats include external factors and trends beyond control that could decrease demand or cause future losses. ${ }^{12,13}$ In the table are summarized SWOT of the given segment. The aim was to achieve the greatest possible objectification of the assessment, the SWOT analysis was created by a multi-disciplinary and international team consisting of a specialist in the development of medical devices (two specialists), development of pharmaceuticals (one specialist), economy (one specialist), and modern technology (three specialists). The role of each team member was to describe partial strengths, weaknesses, the potential opportunities, and threats in their area of work, which corresponded to the individual parts of the analysis of external environment. The team members then carried out quantified evaluation of each item of the European Union (EU) Medical Device Industry according to their significance. Factors were assessed on the scale from 1 to 5 , where 5 stood for the highest significance in relation to the EU countries. Each factor was then assigned with significance, that is, the numeric representation of the significance of its impact on the development in the medical device industry. The sum of significance in each category must be equal to 1 .

\section{The analysis of external environment in the medical device industry \\ The economic situation of the medical device industry}

In economic terms, the current world witnesses a slow growth and in the near future the situation probably will not change much. A little increase in economic activities is expected and the number of unemployed people will decrease only little, if at all. There are still short-term risks represented by problems in the Eurozone, the USA have not overcome fiscal adjustments, and developing countries' economies are slowing down, even though the situation is getting better. Concerning medium-term risks, several developed economies adopted unconventional and risky monetary measures aimed at improving global financial stability. ${ }^{14}$

In relation to the medical device industry, it may be observed that there are unprecedented opportunities looming for the medical device industry in countries such as the People's Republic of China, India, Latin America, the Middle East, and other emerging markets with rising GDP and expanding middle class. The rise in both population and disposable income should lead to a much higher demand for medical devices and medical services. The expansion of medical device companies into developing countries will increase their manufacturing efficiency and decrease the price of their products. They will also be able to better serve local markets.

The medical technology industry, with its established centers in the USA and Western Europe, is becoming a 
flagship of the whole health care sector. Among other things, it manufactures devices facilitating not only prevention, but also diagnosis and the follow-up treatment. Nevertheless, the focus of the medical technology industry is becoming to move eastward to Asia, particularly to the People's Republic of China, which will probably become prominent in the near future. ${ }^{15}$ The medical device industry comprises thousands of firms, predominantly small enterprises with up to 50 employees. The main drivers of innovation in this area are start-ups that are usually financed by venture capital. ${ }^{4}$

The USA is currently both the largest producer and the consumer of medical devices, with approximately $50 \%$ of the world market. It is followed by Japan, the EU, Canada, and Australia, which boast of large and stable markets with medical devices. ${ }^{10}$ Generally speaking, all developed countries witness a significant increase in both production and consumption of medical devices. ${ }^{16}$ The global market is on the rise not only due to higher life expectancy in the developed countries, but also because of new markets in developing countries. Figure 1 shows an increased interest of survey participants in the BRIC (Brazilian, Russian, Indian, and Chinese) markets. Another attractive market is the Mexican one due to a new and much more efficient regulatory system. ${ }^{17}$ Brazil is the leading country with $20 \%$ of small companies, $21 \%$ of medium ones, and $17 \%$ of large companies. It is followed by the People's Republic of China, which is second for both medium and large enterprises, India, on the other hand, boasts of a higher number of small enterprises than the People's Republic of China, which means an easier way to the Indian market for those with lower resources. Some 18\% of American firms and approximately 19\% of EMEA (European, Middle East, and African) companies strive to enter the Brazilian market this year. Concerning Asia-Pacific companies, 29\% of them plan to expand into the Chinese market.

\section{The economic situation of the medical device industry in Europe}

Europe boasts of some 25,000 medical technology companies. Most of them have their headquarters in Germany, the UK, Italy, Switzerland, Spain, and France. 95\% of the medical technology industry comprises small and mediumsized enterprises. Most of them have less than 50 employees. Small and micro-sized firms employ some 575,000 people. The largest share of medical technology industry employees in total employment is in Germany, while the highest number of employees in this industry per capita is in Switzerland and Ireland. Such high numbers of employees prove that the medical technology industry is a significant player in Europe and in its economy. Whereas, in the USA the medical technology industry provides jobs to approximately 520,000 people, the European pharmaceutical industry employs some 675,000 people. In 2012, there were more than 10,000 registered patent applications in this field. The annual investment in R\&D equals approximately 4 billion $€ 19.19$. The medical device industry belongs to one of the most innovative sectors with an average life cycle of only 18 months before an improved product becomes available. ${ }^{11}$

European countries spent on average $10.4 \%$ of their GDP on health care. ${ }^{1}$ Approximately $7.5 \%$ of it is spent on medical technologies. Nevertheless, expenditures on medical technologies vary significantly across Europe. They usually

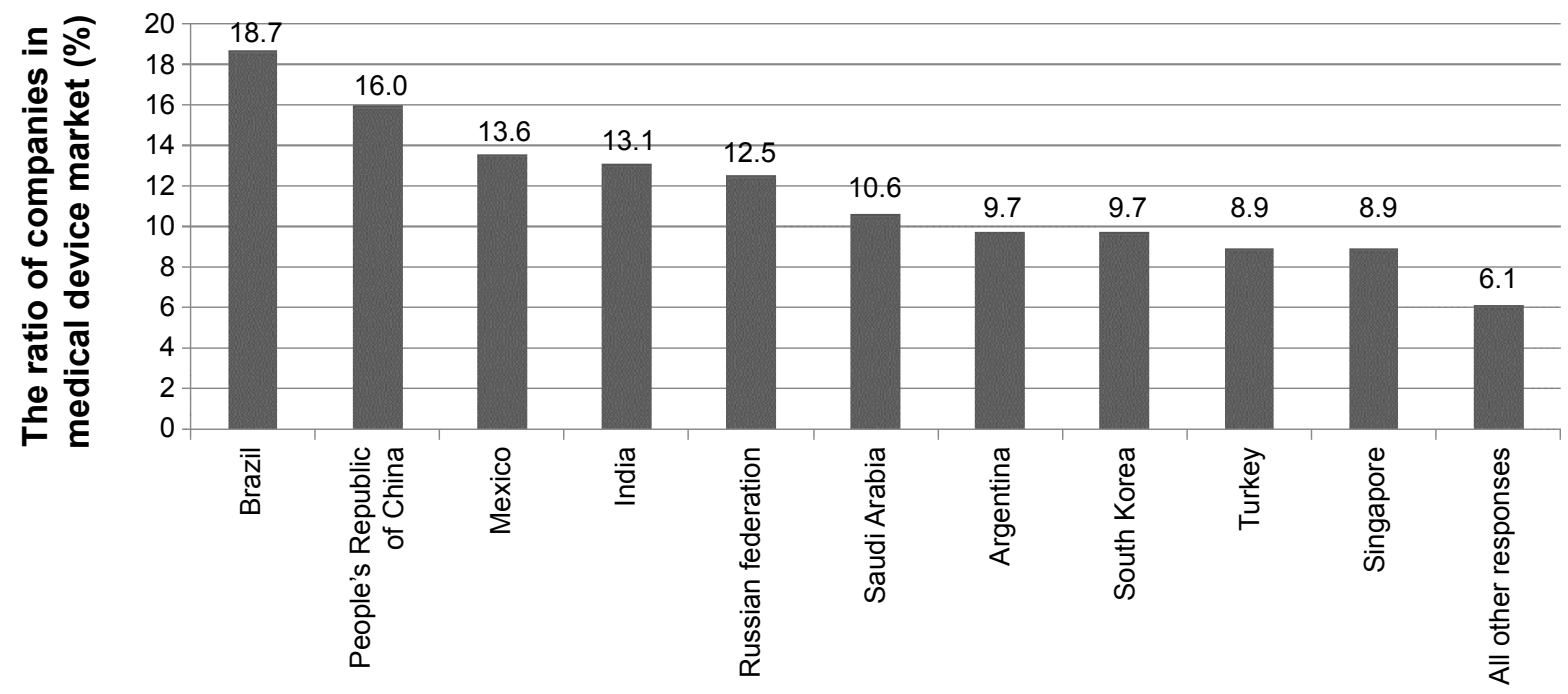

Figure I Interest in the emerging markets.

Note: Data from Emergo Group. ${ }^{18}$ 
range between $5 \%$ and $10 \%$ of total expenditures on health care. European per capita expenditure on medical technologies equals $€ 1,957$ (weighted average), whereas in the USA it is $€ 380$. The average annual growth of the European market over the last 6 years is $4 \%$. Figure 2 shows the development in individual years. The value of the European medical technology market is estimated at some $€ 100$ billion. Medical technologies help solve problems in many areas. Globally, the largest segment is in vitro diagnostics, cardiology comes second, and diagnostic imaging third.

\section{Technological environment of the medical device industry}

The technological factors affecting the economic level include government support for $\mathrm{R} \& \mathrm{D}$, the overall level status of the use of technologies, as well as, for example, new discoveries. ${ }^{19}$ These three areas will also be focused on in connection with the situation in the EU and with the medical devices sector. The economic significance of innovation activities has been growing. Planned state budget R\&D expenditures in the years of 2013, 2014, and 2015 have been approved for $€ 1.036$ million per year. ${ }^{20}$ Up until 2015, the percentage of financial resources for R\&D provided as a special-purpose support should be rising. These expenditures should correspond to the real demand in the application sphere. Institutional support will constitute a significant part of public resources for R\&D. The supported areas will be particularly the transfer of knowledge into practice, patenting, or establishing spinoff companies.

Another key factor of $\mathrm{R} \& \mathrm{D}$ development is risk capital investment, which is private investment in companies dealing with the development of new products and technologies, usually in the initial phase (start-up and seed) or in the expansion phase. The highest level of these investments is in
Bulgaria, Romania, and Greece. The Czech Republic belongs to the category of countries with the lowest risk capital investment. Luxemburg disburses by far the most risk capital investment, followed by Denmark and Hungary. In the context of patent activity, European countries demonstrate re-active constant activity. The maximum value was reached in 2008 , followed by a decline. This development may be affected by the economic crisis and a lack of funding in R\&D.

The medical technology industry is known for the high quality of $R \& D$ as well as for its cooperation with end users, which leads to continuous innovation. An improved version of almost any product is available within 2 years of launching the previous model. In 2012, the European Patent Office counted more than 10,000-plus patent applications in the field of medical technology, which was $7 \%$ of all patent applications. No other technical field achieved such a high figure. European countries filed 38\% of all patent applications in this field. In order to provide a comparison, there were approximately 5,400 patent applications in the pharmaceutical industry and 5,300 applications in the area of biotechnology. Within the last 10 years, the number of European Patent Office medical technology patent applications has doubled, whereas the number of applications in the field of biotechnology and pharmaceutics remained more or less stable. ${ }^{21}$

\section{Political-legal environment}

Significance of the political and legal environment for entrepreneurship is indisputable. As an indispensable part of institutional quality, it directly affects realization and efficiency of entrepreneurial activities and total economic efficiency. Factors related to power distribution and legislative environment are significant in this sector. Government's and other state institutions' activities may significantly influence entrepreneurship on various types of market. This section

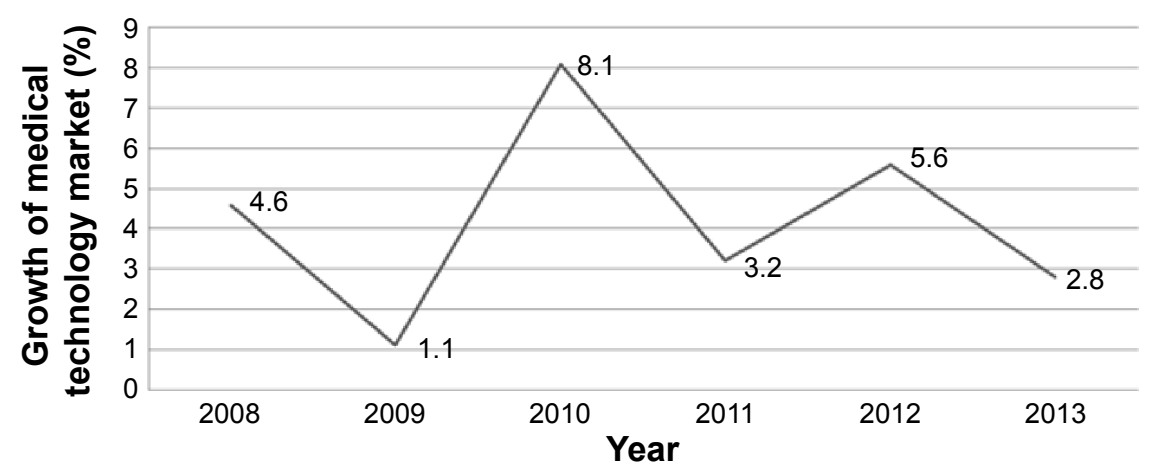

Figure 2 European medical technology market growth rates, based upon the manufacturer process, 2008-2013. Note: Data from Medtech Europe.' 
describes legislation related to a medical device. Regulations in the global market as in the People's Republic of China, Europe, Canada and follow US FDA's model. Medical devices are classified into Classes I, II, and III. Regulatory control increases from Class I to Class III. The device classification regulation defines the regulatory requirements for a general device type.

\section{Medical device regulation in the EU}

Medical device regulation in the EU is governed by three $\mathrm{EU}$ council directives and their subsequent amendments: ${ }^{22}$

- 90/385/EEC on Active Implantable Medical Devices,

- 93/42/EEC on Medical Devices,

- 98/79/EC on In Vitro Diagnostic Medical Devices.

The Directives are supported by guidelines, which, according to the European Commission, are aimed at the promotion of a:

Common approach by manufacturers and Notified Bodies involved in the conformity assessment procedures according to the relevant annexes of the Directives, and by the Competent Authorities charged with safeguarding Public Health.

All medical devices placed on the market in the EU must comply with the relevant Directive. The medical device directive covers a wide range of medical devices, from first-aid bandages and walking frames to implantable devices and computed tomography scanners. The level of medical device assessment therefore varies, according to the perceived risk of the device. For medium and high-risk devices, companies are required to have their quality systems and technical documentation reviewed by a notified body before their products can be placed on the market. The notified body has a responsibility for ensuring that the relevant requirements are met prior to the issue of certification. Manufacturers are then able to place the European Conformity (CE) marking on their products to demonstrate regulatory compliance. The CE marking is recognized throughout the EU, the European Economic Area and Switzerland, which allows these products to be sold over this geographically wide area. Nonetheless, individual states may request registration of medical devices, and may have additional requirements relating to the language of the device information. For manufacturers of Class I or IVD medical devices, it is a legal requirement to provide certain information to a competent authority in an EU member state where they have a registered place of business, prior to marketing their device in the EU. If the company does not have a registered place of business in the $\mathrm{EU}$, they must designate someone who is established in the
EU to act on their behalf. ${ }^{22}$ Potential sources of financing health care and the development of medical devices lie in the following funds: ${ }^{23}$

- the European Regional Development Funds, which strengthens cohesion, namely economic, social, and territorial one, by redressing the balance among various regions,

- the European Social Funds, which is the main instrument of the EU for investing in its citizens,

- Horizon 2020.

These programs are relevant and provide investment opportunities to complement those financed through Structural Funds. Furthermore, the Commission strongly promotes Public-Private Partnerships as a means of improving the levels of investment and innovation in a wide range of public services including health care. ${ }^{24}$

In order to ensure the smooth functioning of a support system, it is necessary to have a clear and efficient legislation, which must be implemented across the whole of the EU in a consistent way and which enables quick access to the latest technologies.

\section{Social environment}

The social and cultural environment is based on demographic situation, employment rate, the population's education and income, etc. It is important to monitor the basic values and attitudes of the population and specific needs of various target groups. The forecast percentage growth in over- 65 and over- 80 inhabitants in the EU countries is illustrated in Figure 3.

In developed economies, aging population will drive the growth of medical device companies. More than $80 \%$ of people aged 65 years or above have at least one chronic disease. People aged 60 years or above will increase significantly 2012 onward when the first wave of those born during the baby boom generation begins to turn 65 years, presenting great opportunities for medical devices companies that bring innovative technologies to address the chronic disease. ${ }^{26}$ Table 1 shows figures of university educated citizens with degrees in the 30-34 years age group. EU strategy target is to achieve $40 \%$ by 2020 . The demographic trend in EU acts strongly against this objective. The Governments of chosen EU countries determined the maximum number of accepted students.

Currently, the real income drops, which results in lower consumer expenditures and the creation of savings. These facts hinder economic growth. Its largest part of income is wages. They differ significantly according to economic activity. The highest income is in finance and insurance, followed by the information and communication sectors. 


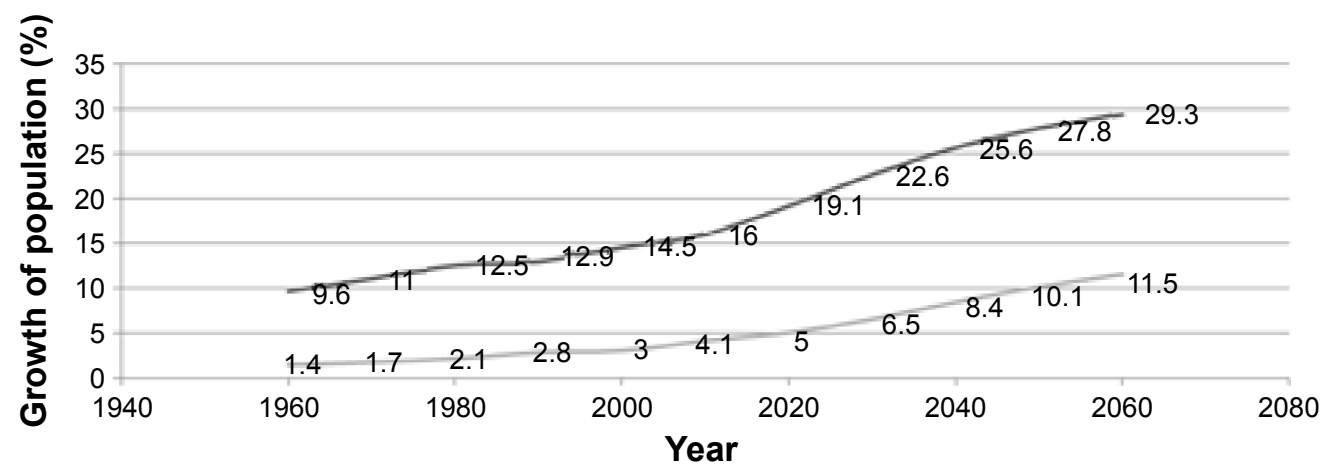

\section{Percentage of population aged 65 years and over on 1st January of selected years}

Percentage of population aged 80 years and over on 1st January of selected years

Figure 3 Aging population.

Note: Data from Eurostat. ${ }^{25}$

\section{Social environment in the medical device industry}

Employment and incomes within the medical device industry is quite complicated to describe. Since the production of medical devices is part of the manufacturing industry category, it is not monitored separately at an international level (Eurostat databases, OECD). According to Eurostat and $\mathrm{OECD}, 15,400$ industry professionals are in the medical device industry. The median salary grew by $5 \%$, to $\$ 105,000$ between 2012 and 2013. The rising demand for employees in the areas of quality and regulatory affairs is also reflected in earnings. Salaries for quality assurance and quality control professionals increased more than $3 \%$ in 2013 .

\section{The situation of medical device industry - SWOT analysis}

The aforementioned analysis of external environment (economic, legislative, social, and technological) described the most significant impacts on the medical device industry. Table 2 specifies SWOT in this industry. In the Criterion column, the experts assessed the significance of each item on the scale from 1 to 5 as it is described in the "Research methods" section. On the scale $0-1$, the significance was given to each item in four categories (strengths, weakness, opportunities, and threats) of the SWOT analysis (the sum must equal to 1 ). The Total Impact column was created as the product of "Criteria*Significance" (Table 2).
With respect to the aforementioned trends in the medical device industry, it can be maintained that it is a very prospective field. Nevertheless, investments in it may have their advantages as well as drawbacks and provide companies with many opportunities.

Among the most significant strengths of the medical device industry in the EU are, in comparison with other sectors, relatively high expenditures on health care $(0.75)$ and medical technologies, an increasing growth in science and research expenditures, quality research centers, and qualified workforce (0.8).

All factors related to the scattered and dissonant EU administration and legislation (0.4) as well as insufficient interconnection between scientific research institutions and practice $(0.72)$ create obstacles to the growth of this industry's efficiency. In addition, a very crucial weakness is a significant threat to the future when it will be necessary to work on improving the cooperation among universities, scientific research institutes, and institutions, supporting innovative entrepreneurship capacities of science and technology parks. In this industry, it is also essential to pay attention to the long-run development goals. The continuing stagnation of the EU economy (0.1) and underrated R\&D cooperation in clusters $(0.85)$ were marked as a threat with relatively smaller significance.

Future opportunities in the medical device industry is aging population (1) and clear vision (0.4) in developed

Table I Total number of people in tertiary education in the EU (\%)

\begin{tabular}{llllllllllllll}
\hline Year & 2000 & $200 I$ & 2002 & 2003 & 2004 & 2005 & 2006 & 2007 & 2008 & 2009 & 2010 & $20 I I$ & $20 I 2$ \\
\hline EU average & 22.4 & 22.8 & 23.5 & 25.0 & 26.9 & 28.0 & 28.9 & 30.0 & 31.0 & 32.2 & 33.5 & 34.6 & 35.8 \\
\hline
\end{tabular}

Note: Data from Eurostat. ${ }^{25}$

Abbreviation: EU, European Union. 
Table 2 SWOT analysis of the EU medical device industry

\begin{tabular}{|c|c|c|c|}
\hline & Criterion & Significance & Total impact \\
\hline \multicolumn{4}{|l|}{ Strengths } \\
\hline High expenditures on health care, particularly on medical technologies & 5 & 0.15 & 0.75 \\
\hline Well-developed industry with a strong manufacturing base & 3 & 0.08 & 0.24 \\
\hline Macroeconomic and price stability of the sector & 2 & 0.05 & 0.1 \\
\hline Quality research centers & 4 & 0.15 & 0.6 \\
\hline Increasing annual growth of science and research expenditures & 4 & 0.12 & 0.48 \\
\hline Existing qualified workforce & 4 & 0.2 & 0.8 \\
\hline Existing strategic development goals & 4 & 0.1 & 0.4 \\
\hline Existing and new business incubators and science and technology research parks & 3 & 0.1 & 0.3 \\
\hline Growth of the medical device industry & 4 & 0.05 & 0.2 \\
\hline Total & & I & \\
\hline \multicolumn{4}{|l|}{ Weaknesses } \\
\hline Disunited legislative environment in EU countries & 4 & 0.1 & 0.4 \\
\hline Administratively demanding system of public support & 4 & 0.08 & 0.32 \\
\hline Fragmented consultancy in the fields of public support subsidies and legislation & 3 & 0.1 & 0.3 \\
\hline A lack of strong linkages between industries and academia & 4 & 0.18 & 0.72 \\
\hline Insufficient coordination and standardization of the medical device industry development & 3 & 0.12 & 0.36 \\
\hline Uncooperative research centers & 3 & 0.17 & 0.51 \\
\hline Legislative difficulties of transferring scientific results in company practice & 4 & 0.1 & 0.4 \\
\hline Low utilization of risk capital to financing & 2 & 0.1 & 0.2 \\
\hline Total & & I & \\
\hline \multicolumn{4}{|l|}{ Opportunities } \\
\hline $\begin{array}{l}\text { Favorable demographics, namely an aging population in the developed world and a higher } \\
\text { number of active elderly people will lead to an increase in demand for medical devices } \\
\text { and medical services }\end{array}$ & 5 & 0.2 & I \\
\hline $\begin{array}{l}\text { Medical device industry is expected to grow in countries like the People's Republic of China } \\
\text { with their expanding middle class in emerging markets }\end{array}$ & 4 & 0.1 & 0.4 \\
\hline Significant export potential to the developing as well as developed countries & 5 & 0.05 & 0.25 \\
\hline Existence of clear visions, objectives and strategies for the future & 5 & 0.08 & 0.4 \\
\hline Development of existing and new clusters in the field of the medical device industry & 2 & 0.07 & 0.14 \\
\hline Increased accessibility of risk capital sources for financing companies' developmental activities & 2 & 0.1 & 0.2 \\
\hline Purpose-oriented financing of science and research & 4 & 0.1 & 0.4 \\
\hline Coordination of scientific research institutes & 4 & 0.15 & 0.6 \\
\hline Coordination and unification of law related to the medical device industry & 4 & 0.15 & 0.6 \\
\hline Total & & I & \\
\hline \multicolumn{4}{|l|}{ Threats } \\
\hline Continuing stagnation of the EU economy & 3 & 0.1 & 0.3 \\
\hline Financial and time difficulties involved in the development of innovative medical devices & 3 & 0.08 & 0.24 \\
\hline Underestimated significance of marketing for entering foreign markets & 4 & 0.1 & 0.4 \\
\hline Underrated R\&D cooperation in clusters & 3 & 0.1 & 0.3 \\
\hline A lack of workplaces with efficient systems for transferring science and research results & 3 & 0.18 & 0.54 \\
\hline Preference given to short-term development goals & 5 & 0.15 & 0.75 \\
\hline $\begin{array}{l}\text { Little use of cooperation and connections among universities, scientific research institutes } \\
\text { and institutions supporting innovative entrepreneurship capacities }\end{array}$ & 5 & 0.17 & 0.85 \\
\hline Total & & 1 & \\
\hline
\end{tabular}

Notes: Criterion of each item on the scale from I to 5. The total impact column was created as the product of "Criteria*Significance".

Abbreviations: EU, European Union; R\&D, research and development.

countries. objectives and strategies. Last but not least, also the unification and clarification of legislative requirements.

\section{Discussion}

The results from the aforementioned SWOT analysis can be compared with similar studies ${ }^{7,15,27,28}$ carried out in this sector in advanced and emerging economies as well as in the European and non-European countries (Table 3). The studies of the chosen economics such as the USA, the UK, or Israel describe current situation of the medical device industry in the developed countries. The opportunities and threats are completely different in comparison with studies of the emerging countries such as Mexico, Turkey, or the People's Republic of China.

Table 3 summarizes SWOT analysis items for both developed and developing countries. The third column 


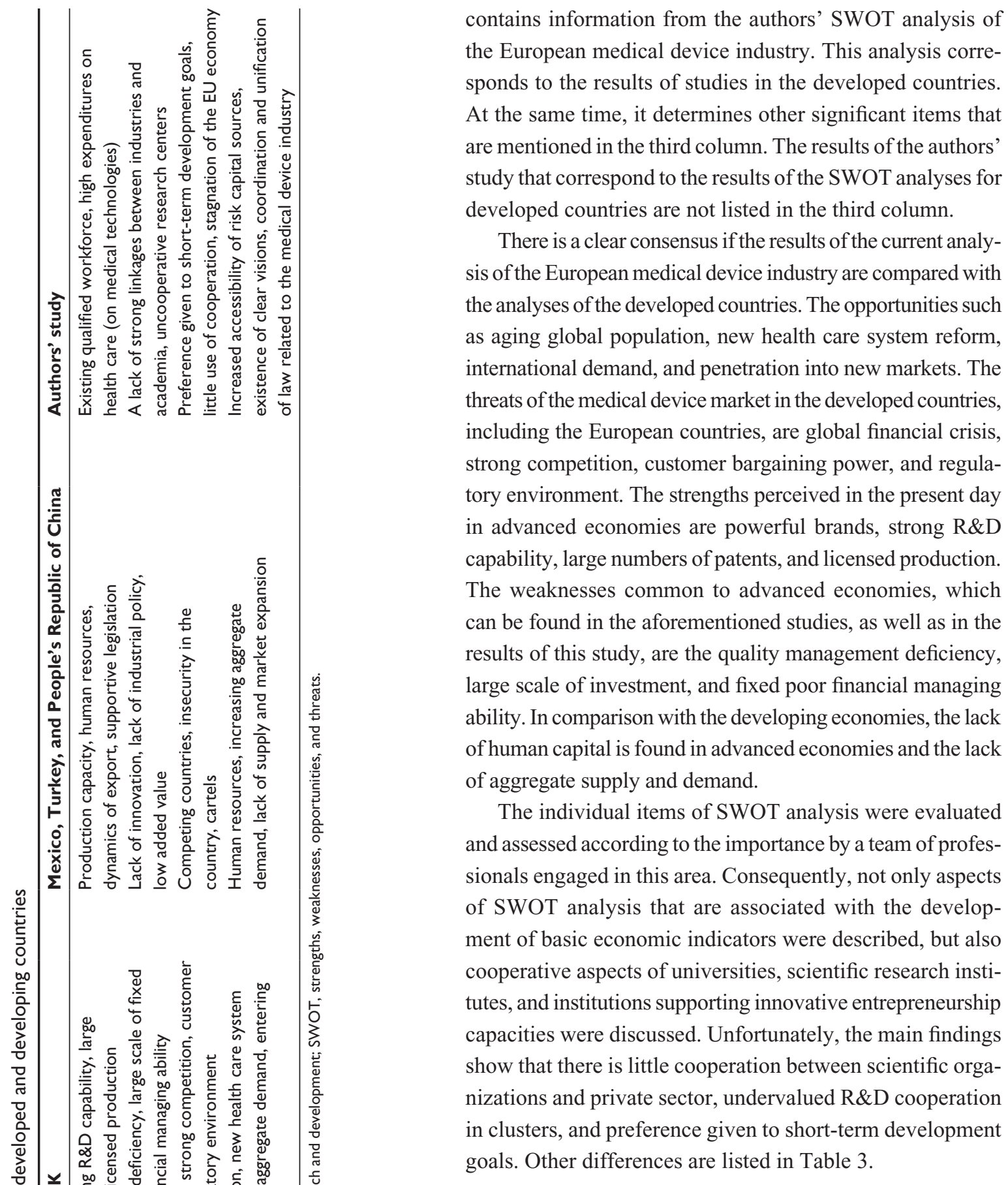

\section{Conclusion}

The medical device industry directly as well as indirectly, by ensuring better health of the population, influences the economic situations in each country. ${ }^{29,30}$ Moreover, despite the fact that the economic recession still continues in many countries, this industry is characterized by a slight growth. As far as its future development is concerned, the medical device industry may look for new opportunities for its development in the developed economies, and the expanding middle class in emerging nations, in aging population and more active 


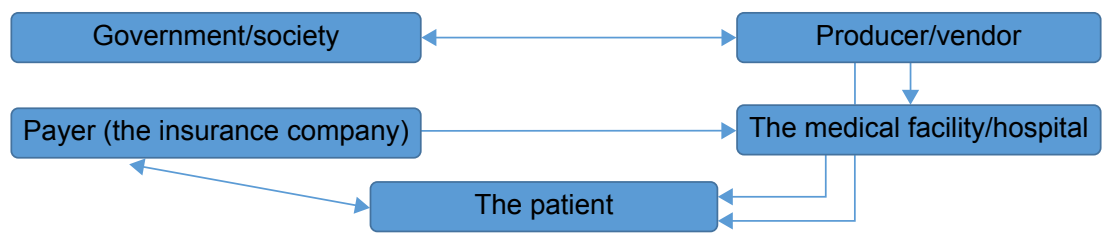

Figure 4 Financing among individual entities.

seniors. The medical device industry will move with the general market and will grow moderately. On the other hand, there are several threats that should not be underrated as they may badly influence the medical device industry and worsen its competitiveness. For instance, global competition in world markets, low coordination of research activities within the EU, or complicated administrative procedures.

Experts are in wide agreement that advances in medical technology will fundamentally transform health care and delivery systems over the next decade by providing new solutions that will challenge existing paradigms and revolutionize the way treatments are administered. Critical elements in decisionmaking about investments in developing new medical devices are the knowledge of market needs, awareness of benefits to society, and last but not least benefits for the health care system by decreasing expenditures on a given type of disease or condition. Figure 4 illustrates possible costs between the various entities. The primary payer for many types of medical device is the insurance company, not the patient.

In the future, the system for solving the investment assessing in medical device development will be important in the future in the developed countries. Reasons are as follows:

- limited financial resources of governments in the developed countries and an effort to spend effectively on R\&D,

- investments in the development and production of medical devices in relation to the growth of this market seems to be prospective in the private sector,

- a growing number of patients who live longer thanks to the high-quality health care.

\section{Acknowledgments}

This work was supported by a project at the University of Hradec Kralove titled Excellence FIM UHK 2015. It was also supported by the long-term development plan FNHK.

\section{Disclosure}

The authors report no conflicts of interest in this work.

\section{References}

1. Medtech Europe. The European Medical Technology Industry in Figures; 2013. Available from: http://www.eucomed.org/uploads/Modules/Publications/ the_emti_in_fig_broch_12_pages_v09_pbp.pdf. Accessed May 10, 2015.
2. Bergsland J, Elle OJ, Fosse E. Barriers to medical device innovation. Med Dev Evid Res. 2014;7:205-209.

3. Adang E. Economic evaluation of innovative technologies in health care should include a short-run perspective. Eur J Health Econ. 2008;9(4): 381-384.

4. Meidata. Israel Medical Devices Industry - Market Overview; 2012. Available from: http://www.slideshare.net/Israeltrade/meidata-tamatisrael-medical-devices-industry-market-overview. Accessed May 10, 2015.

5. Barro R. Health and Economic Growth. Mimeo; 1996. Cambridge, MA: Harvard University.

6. Barro R, Lee J. Sources of economic growth. Carnegie-Rochester Conf Ser Public Pol. 1994;40:1-46.

7. Rios MS, Sánchez MCC, Porcayo DHO, Blat JMM. Roadmap for the Medical Device Industry, Mexico City; 2012.

8. Gupta P, Janodia MD, Jagadish PC. Medical device vigilance systems: India, US, UK, and Australia. Medl Dev Evid Res. 2010;(3):67-79.

9. Swan T. Economic growth and capital accumulation. Econ Rec. 1956; 32:334-361.

10. European Commission (EC). Investing in Health. Commission Staff Working Document; 2013. Available from: http://ec.europa.eu/ health/strategy/docs/swd_investing_in_health.pdf. Accessed May 10, 2015.

11. European Commission (EC). Medical Device - Competitiveness. European Commission Website of Public Health; 2013. Available from: http://ec.europa.eu/health/medical-devices/competitiveness/ index_en.htm. Accessed May 10, 2015.

12. Nadine Pahl, Anne Richter. SWOT Analysis - Idea, Methodology and A Practical Approach. Bod Third Party Titles; 2009.

13. Cadle J, Paul D, Turner P. Business Analysis Techniques: 99 Essential Tools for Success. The Chartered Institute for IT: Bod Third Party Titles; 2014.92.

14. United Nations. World Economic Situationand Prospects 2013. United Nations Publication; 2013. Available from: http://www.un.org/en/ development/desa/policy/wesp/wesp2013/wesp13update.pdf. Accessed May 10, 2015.

15. The World Bank. China Overview; 2014. Available from: http://www. worldbank.org/en/country/china/overview. Accessed May 10, 2015.

16. European Commission (EC). Medical Device. European Commission website in the Czech Republic; 2014. Available from: http://ec.europa. eu/health/medical-devices/index_cs.htm. Aaccessed May 10, 2015.

17. Marešová P, Kuča K. Porter's five forces on medical device industry in Europe. Mil Med Sci Lett (Voj Zdrav Listy). 2014;83(4):134-144.

18. Emergo Group. Outlook for the medical device industry in 2014. Annual Survey; 2014. Available from: http://www.emergogroup.com/research/ annual-medical-device-industry-survey. Accessed May 10, 2015.

19. CzechMed. Výrobci zdravotnických prostředků varuji před evropskou legislativou. Zpravodajský portál farmakologie; 2013. Available from: http://lekarenstvi.apatykar.info/lekarenstvi-u-nas/clanek-2569/. Accessed May 10, 2015.

20. Council for Research, Development and Innovation. Expenditures of the state budget of the Czech Republic in the research, development and innovation in 2013 with a view to the years 2014 and 2015; 2013. Office of the Government of the Czech Republic.

21. European Patent Office. Eucomed Calculations; 2012. Available from: http://www.eucomed.org/uploads/Modules/Publications/the_emti_in_ fig_broch_12_pages_v09_pbp.pdf. Accessed May 10, 2015. 
22. Espicom Business Intelligence. Medical Devices Pricing \& Reimbursement; 2014. Available from: http://www.espicom.com/medical-devicespricing-reimbursement-2014.html. Accessed May 10, 2015.

23. Coggi PT. Investice do zdraví je prioritou pro tzv. sociální investiční baliček. European Commission Website in the Czech Republic; 2013. Available from: http://ec.europa.eu/health/newsletter/106/ focus_newsletter_cs.htm. Accessed May 10, 2015.

24. Dowdeswell B. Structural Fund Investment in the Health Sector Context and Policy Framework. The Report of European Centre for Health Assets and Architecture; 2013. Available from: www.mzcr.cz/Soubor. ashx. Accessed May 10, 2015.

25. Eurostat. European Database; 2015. Available from: http://ec.europa. eu/eurostat. Accessed May 10, 2015.

26. Patil N. Healthcare (Medical Devices and Equipment). Report of Henry Fund program, the University of Iowa; 2012. Available from: tippie. uiowa.edu/henry/apply.cfm. Accessed May 10, 2015.
27. United Nations. World Economic Situation and Prospects 2014: Global Economic Outlook. United Nations Publication; 2014. Available from: http://www.un.org/en/development/desa/publications/wesp2014firstchapter.html. Accessed May 10, 2015.

28. Zhe L, Xiaotong W. Analysis on Opportunities and Challenges of Chinese Medical Device Industry under New Health Care Reform Reference of Sweden, USA and UK; 2010. Degree Project, Master of Business Administration, Karlstads universitet.

29. Bergsland J, Elle OJ, Fosse E. Barriers to medical device innovation. Med Dev Evid Res. 2014;7:205-209.

30. Lang AR, Martin JL, Sharples S, Crowe JA. Medical device design for adolescent adherence and developmental goals: a case study of a cystic fibrosis physiotherapy device. Patient Prefer Adher. 2014;8:301-309.
Therapeutics and Clinical Risk Management

\section{Publish your work in this journal}

Therapeutics and Clinical Risk Management is an international, peerreviewed journal of clinical therapeutics and risk management, focusing on concise rapid reporting of clinical studies in all therapeutic areas outcomes, safety, and programs for the effective, safe, and sustained use of medicines. This journal is indexed on PubMed Central, CAS,

\section{Dovepress}

EMBase, Scopus and the Elsevier Bibliographic databases. The manuscript management system is completely online and includes a very quick and fair peer-review system, which is all easy to use. Visit http://www.dovepress.com/testimonials.php to read real quotes from published authors. 